\title{
DISLOCATIONS AT THE CERVICOTHORACIC JUNCTION
}

\author{
D. K. EVANS
}

\author{
From Lodge Moor Spinal Injuries Unit, Sheffield
}

\begin{abstract}
Dislocations of the cervicothoracic junction are frequently missed. Experience of this rare injury over 27 years at the Spinal Injuries Unit in Sheffield confirms that nearly two-thirds were not properly diagnosed on admission. Only two of the 14 dislocations studied were reduced by conservative methods and these were both associated with fractures of the posterior bony elements. Open reduction is necessary to replace pure dislocations at the C7-T1 level. It seems likely that the spinal cord lesion is not influenced by reduction of the displacement. The three patients who had an incomplete lesion of the spinal cord made excellent neurological recoveries although none of the dislocations was reduced. It is concluded that on theoretical grounds it is justified to embark on operative reduction of displacements at this spinal level only if the cord lesion is incomplete, nerve root recovery therefore possible, and if the operation can be brought about soon after the injury.
\end{abstract}

Failure to recognise cervical displacements or instability after injury occurs in three circumstances.

If the patient has been rendered unconscious by an injury to the head, the intracranial injury then overshadows the associated neck injury. The remedy is to take radiographs of the cervical spine of all patients suffering a head injury that is severe enough to produce unconsciousness.

If the cervical injury has damaged ligaments (usually the posterior complex) and produced a subluxation which has spontaneously reduced, radiographs then appear normal. Any patient who has marked symptoms or physical signs in the neck after injury, but has normal routine radiographs, should have further radiographs performed with the neck under flexion and extension strain (Figs 1 and 2). Such strain radiography is routine in the investigation of ligamentous injuries in the knee and ankle and should be practised more often in cervical injuries (Evans 1976; Webb et al. 1976).

If the cervical injury has occurred at the C7-T1 level, routine lateral radiographs frequently fail to show this area, more especially if the patient is bull-necked and heavily built with well-developed shoulders. Difficulty should be anticipated in such patients and lateral radiographs taken with the head steadied by a halter and the arms pulled downwards by an assistant (Fig. 3). The "swimmer's" view (Fig. 4) may be revealing: for this the $x$-ray tube is centred above the shoulder remote from the film and pointed towards the contralateral axilla adjacent to the film with the table angled 10 to 15 degrees to the head (Fig. 5). Even this manoeuvre fails at times and tomography must then be employed (Fig. 6). Evidence of

D. K. Evans, FRCS, Consultant Orthopaedic Surgeon Hallamshire Hospital, Glossop Road, Sheffield S10 2JF, England.

(C) 1983 British Editorial Society of Bone and Joint Surgery 0301-620X/83/2024-0124\$2.00

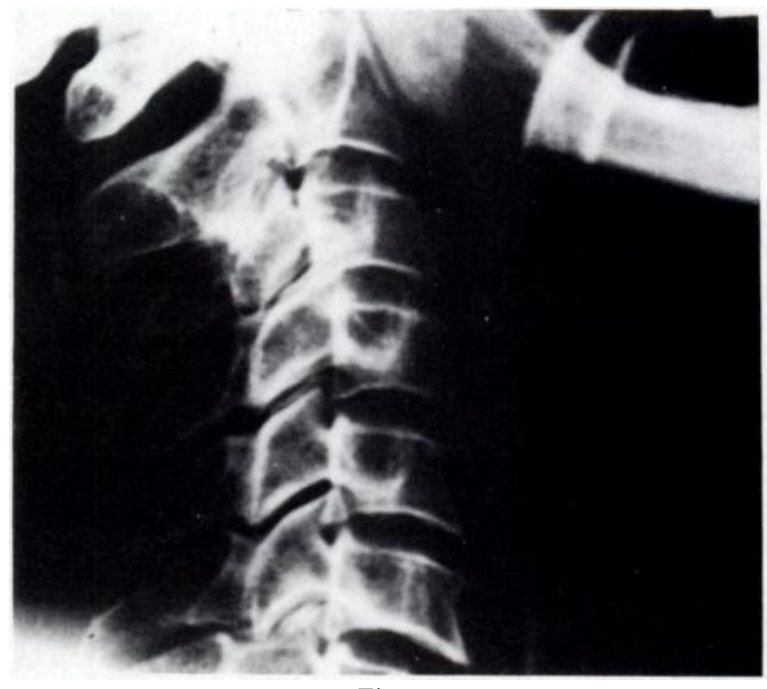

Fig. 1

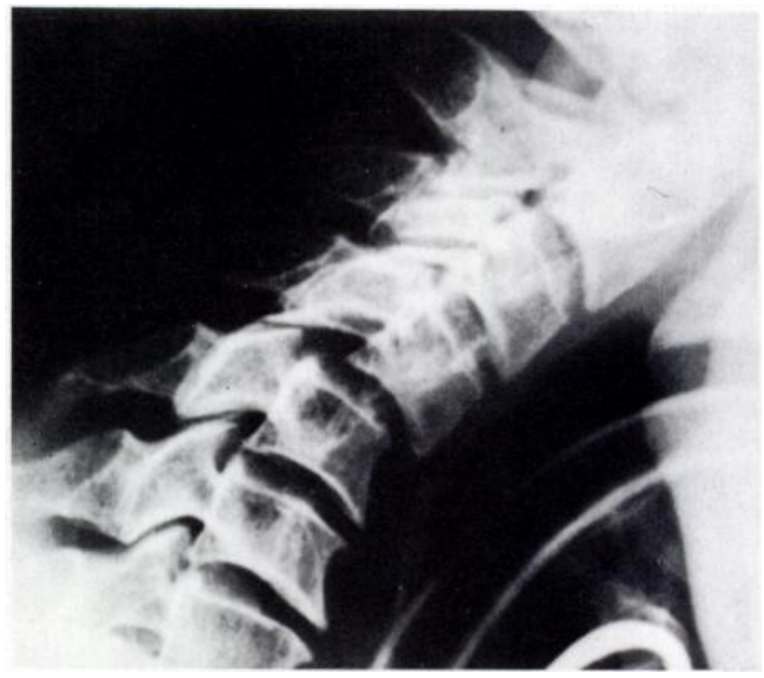

Fig. 2

Lateral radiographs under flexion and extension strain showing instability in flexion at C4-5. 


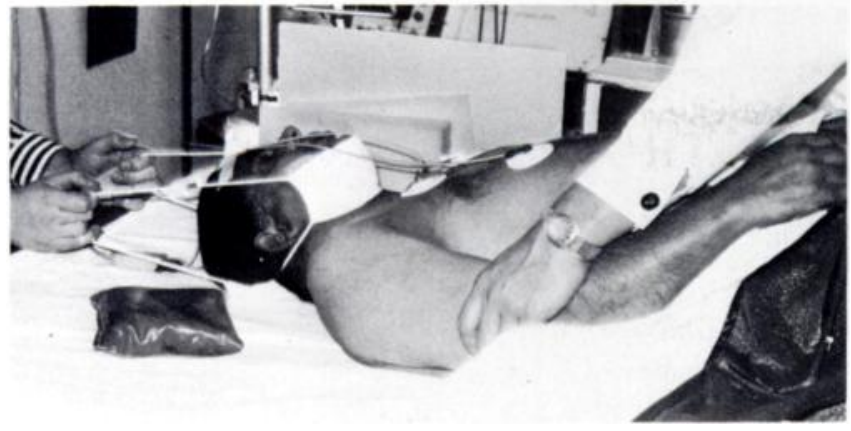

Fig. 3

Pulling the shoulders down to show the lower cervical spine. displacement of the posterior facets can often be seen (even if the vertebral bodies are not clear) by oblique views taken at 45 degrees (Fig. 7).

\section{CLINICAL MATERIAL}

From November 1954, when the Spinal Injuries Unit moved to Lodge Moor Hospital, to December 1980, 1315 patients with new spinal injuries and partial or complete paralysis were admitted to the unit. Of these, 587 had a cervical injury, 14 of whom had a dislocation or fracturedislocation at the C7-T1 level (Table I). All these patients

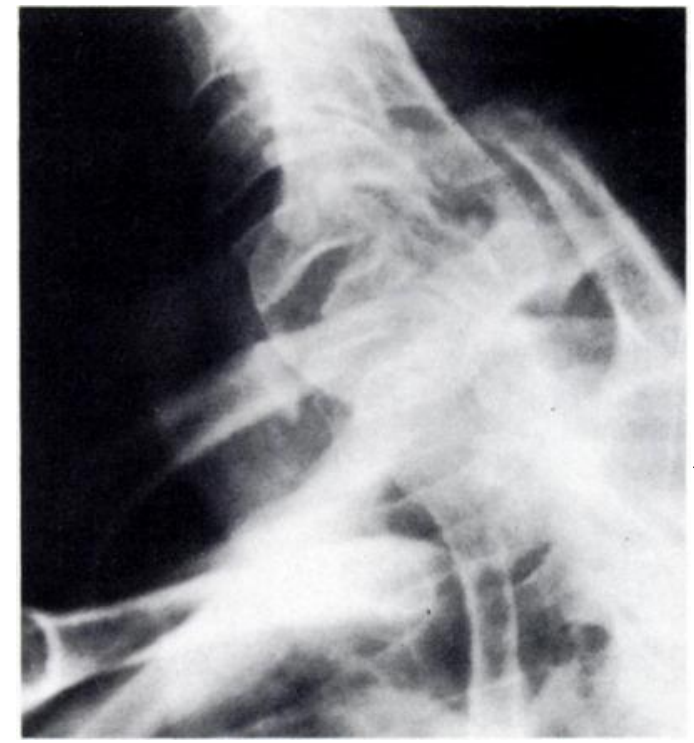

Fig. 4

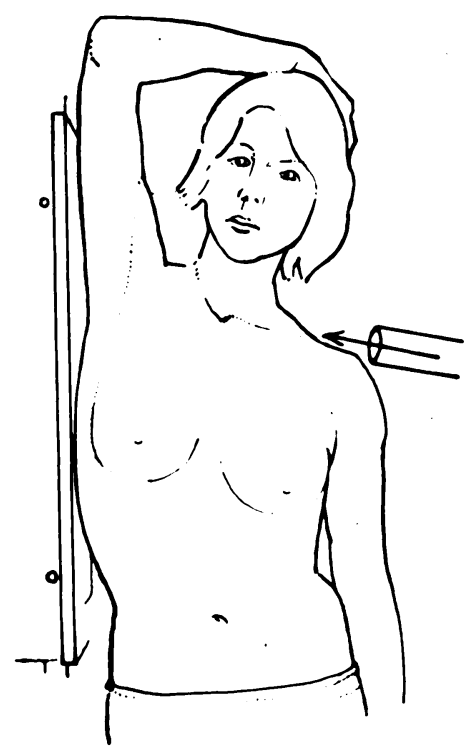

Fig. 5

Figure 4-The "swimmer's" view. Figure 5-The radiographic technique.

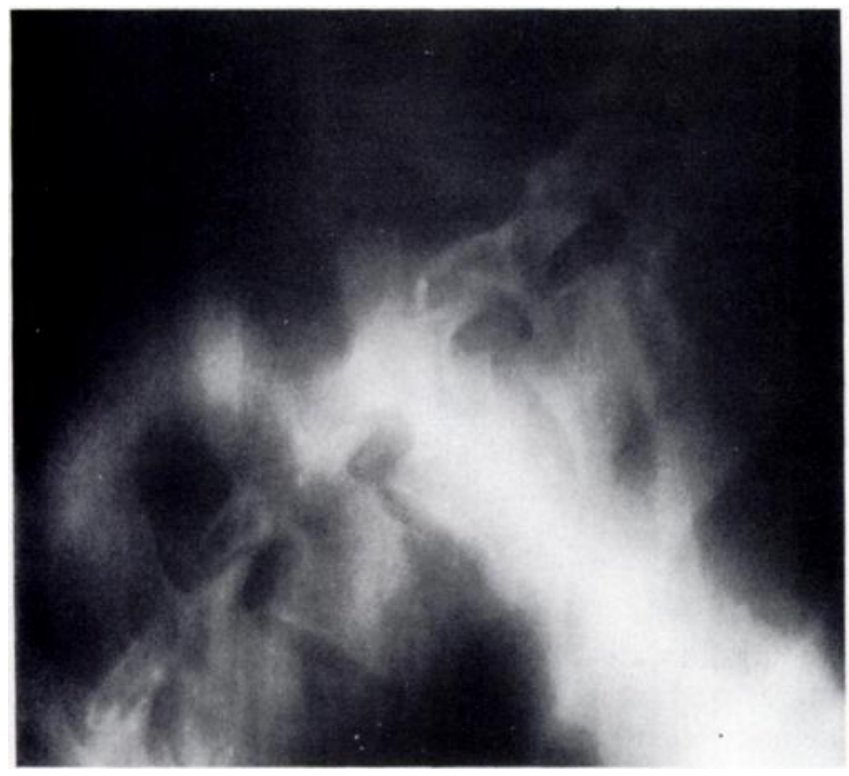

Fig. 6

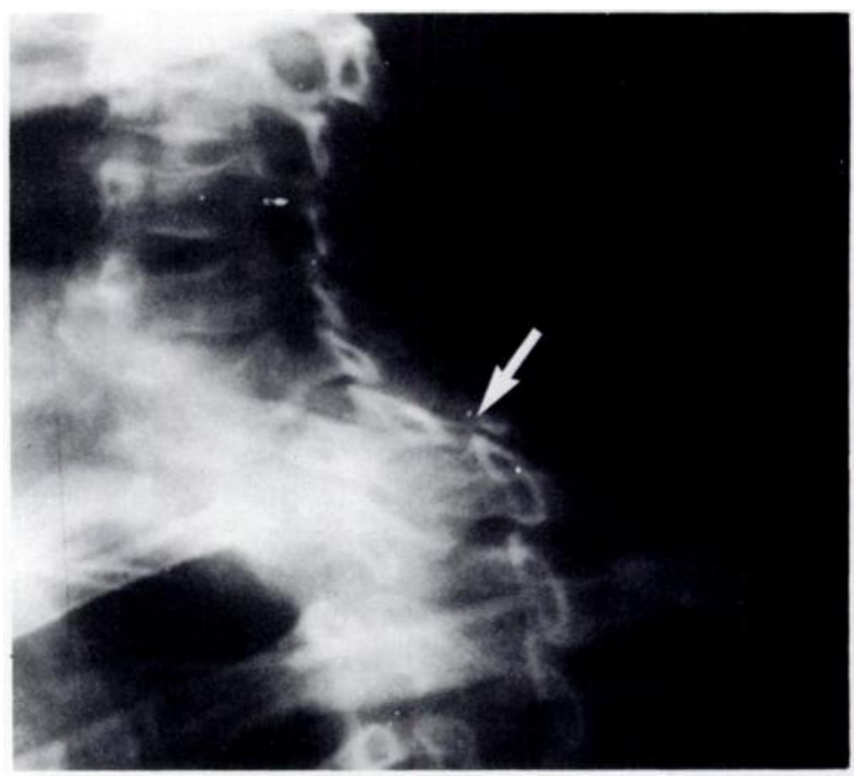

Fig. 7

Figure 6-Tomography gives an indistinct picture, but may be the only method of determining the level of the bony lesion. Figure $7-0$-blique radiograph (at 45 degrees) showing posterior joint displacement. 
Table I. C7-T1 dislocations

\begin{tabular}{|c|c|c|c|c|c|c|c|}
\hline Case & $\begin{array}{l}\text { Year of } \\
\text { injury }\end{array}$ & $\begin{array}{l}\text { Age } \\
\text { (years) }\end{array}$ & Diagnosed initially & Neurological lesion & Treatment & Reduction & Outcome 1981 \\
\hline 1 & 1954 & 31 & No & $\begin{array}{l}\text { Complete cord lesion } \\
\text { below C8 }\end{array}$ & None & No & $\begin{array}{l}\text { Complete paralysis until } \\
\text { death } 1981\end{array}$ \\
\hline 2 & 1956 & 24 & $\begin{array}{l}\text { No (fracture- } \\
\text { dislocation) }\end{array}$ & Complete below C8 & Skull traction & Yes & $\begin{array}{l}\text { Partially reduced. Remained } \\
\text { completely paralysed. Died } \\
1973\end{array}$ \\
\hline 3 & 1962 & 25 & Yes & Incomplete & $\begin{array}{l}\text { Manipulations } \\
\text { on days } 1 \text { and } 5\end{array}$ & No & $\begin{array}{l}\text { Cerebral abscess-- } \\
\text { hemiparesis. Walks with } \\
\text { calipers }\end{array}$ \\
\hline 4 & 1965 & 40 & $\begin{array}{l}\text { Yes (fracture- } \\
\text { dislocation) }\end{array}$ & Complete below C6 & Skull traction & Yes & $\begin{array}{l}\text { Died at } 7 \text { weeks-pulmonary } \\
\text { embolus }\end{array}$ \\
\hline 5 & 1968 & 39 & No & Complete below $\mathrm{Tl}$ & $\begin{array}{l}\text { Manipulation on } \\
\text { day } 2\end{array}$ & No & $\begin{array}{l}\text { Remains completely } \\
\text { paralysed }\end{array}$ \\
\hline 6 & 1970 & 25 & Yes & Complete below $\mathrm{TI}$ & Skull traction & No & $\begin{array}{l}\text { Remains completely } \\
\text { paralysed }\end{array}$ \\
\hline 7 & 1971 & 27 & No & Complete below C8 & Skull traction & No & $\begin{array}{l}\text { Remains completely } \\
\text { paralysed }\end{array}$ \\
\hline 8 & 1971 & 50 & No & Complete below $\mathrm{C} 7$ & Skull traction & No & $\begin{array}{l}\text { Died at } 10 \text { days-pulmonary } \\
\text { embolus }\end{array}$ \\
\hline 9 & 1974 & 54 & No & $\begin{array}{l}\text { Complete motor loss } \\
\text { Sensory sparing }\end{array}$ & Skull traction & No & $\begin{array}{l}\text { Walked with } 1 \text { stick before } \\
\text { death } 1976 \text { - unrelated cause }\end{array}$ \\
\hline 10 & 1975 & 25 & $\begin{array}{l}\text { Not recognised as neck } \\
\text { injury for } 6 \text { days }\end{array}$ & $\begin{array}{l}\text { Incomplete for } 6 \text { days; } \\
\text { then complete when } \\
\text { sat out of bed }\end{array}$ & $\begin{array}{l}\text { Skull traction } \\
\text { Attempted } \\
\text { manipulation } \\
\text { and open } \\
\text { reduction }\end{array}$ & No & Almost full motor recovery \\
\hline 11 & 1977 & 36 & No & Complete below $\mathrm{C} 7$ & Skull traction & No & $\begin{array}{l}\text { Remains completely } \\
\text { paralysed }\end{array}$ \\
\hline 12 & 1977 & 56 & No & Complete below $\mathrm{C} 7$ & Skull traction & No & $\begin{array}{l}\text { Died at } 7 \text { days-pulmonary } \\
\text { embolus }\end{array}$ \\
\hline 13 & 1980 & 47 & Yes & Complete below $\mathrm{C} 7$ & Skull traction & No & $\begin{array}{l}\text { Remains completely } \\
\text { paralysed }\end{array}$ \\
\hline 14 & 1981 & 57 & $\begin{array}{l}\text { Yes (fracture- } \\
\text { dislocation) }\end{array}$ & Complete below C5 & Skull traction & No & $\begin{array}{l}\text { Died at } 10 \text { days-pulmonary } \\
\text { embolus }\end{array}$ \\
\hline
\end{tabular}

were referred to Sheffield soon after admission to an accident unit in another centre; only five had been correctly diagnosed.

Eleven patients had suffered a complete lesion of the spinal cord, and their paralysis remained complete. Four of them died within seven weeks, all from massive pulmonary emboli. The only two patients whose cervical displacement was reduced (by closed skeletal traction) had complete cord lesions, and reduction did not influence the neurological state. Both these patients had a posterior fracture-dislocation.

Three patients had incomplete spinal cord damage. Only one (Case 3 ) was correctly diagnosed at the original accident centre, and closed reduction by manipulation under general anaesthesia was attempted but failed; a second attempt on the fifth day after injury also failed. Despite a cerebral abscess, which developed after penetration of skull tongs and resulted in a temporary hemiparesis, this patient now walks with crutches. The second incomplete lesion (Case 10) was associated with a head injury and no radiographs were taken until the sixth day when complete paraplegia occurred after the patient was sat out of bed. An attempt at open reduction of the dislocation was made but the displacement was by then irreducible. This patient subsequently made an almost complete recovery and now, seven years after the injury, is able to walk without aids and has only slight impairment of grip with both hands. The third incomplete cord lesion (Case 9) was also missed at the first accident centre and the dislocation was not reduced. The motor paralysis was at first total, although there was some sensory sparing. Neurological recovery proceeded so well that the patient eventually walked with one stick.

\section{DISCUSSION}

The diagnosis of displacements at the C7-T1 level is not unduly difficult if the possibility of injury is borne in mind, and certain radiographic techniques used to demonstrate the whole length of the cervical spine. Once diagnosed, should the dislocation be reduced? This is an important question to be answered in dislocations at this level because closed skull traction, even with weights up 
to 50 pounds, will fail to reduce dislocations not associated with fractures. Similarly, closed manipulation under general anaesthesia will almost certainly fail. The author has failed repeatedly to reduce dislocations at this level despite a fair degree of experience in the technique of manipulation, and an 85 per cent success rate in 80 attempts at higher cervical levels when using the method advocated in 1961 (Evans 1961). The manoeuvre is performed in stages: first traction, then flexion while keeping up the traction, followed by lateral flexion away from the dislocated facet; the displaced facet is then repositioned carefully by rotating the head back to the extended position.

Reduction of dislocations at the cervicothoracic junction requires an open operation, with its attendant risks. It has been the experience of many that quick and gentle replacement of cervical dislocations leads to a surprisingly rapid recovery of function in apparently severely paralysed patients. Burke and Berryman (1971) state "we have repeatedly seen rapid neurological improvement following the successful reduction of dislocations complicated by root lesions or incomplete tetraplegia". They were considering manipulative reduction and not operative reduction. On the other hand Dall (1972) stated that the major determinant of overall prognosis is the nature and magnitude of the initial injury to the spinal medulla. White, Southwick and Pangabi (1976) agreed with this view and added "... the subsequent in-hospital reduction (whether closed or open) may not significantly affect the prognosis". Hardy (1965), in a comparison of operative and conservative management of fracture-dislocation at the thoracolumbar level, reached a similar conclusion that "the pattern of spinal cord damage ... is established at the time of the initial injury". Shrosbree (1979), in a study of 302 cases of cervical dislocations, showed that in unilateral facet dislocation there was no significant difference in cord recovery whether or not the dislocation was reduced. In bilateral facet dislocation his results just favoured reduction over non-reduction.

Does reduction of the displacement improve nerve root function of that level? Brackman and Vinken (1967), in a study of a small group of unilateral facet dislocations, suggested that root symptoms were more likely to improve if the dislocation was reduced. The numbers were so small, however, as to be insignificant. In the present series six of the 11 complete cord lesions were at a higher level in the cord than the $\mathrm{C} 8$ root which emerges from the bony spine at the level of dislocation. In the other five cases the $\mathrm{C} 8$ root showed some function. In all three patients with incomplete tetraplegia excellent function in the $\mathrm{C} 8$ and $\mathrm{T} 1 \mathrm{nerve}$ roots was noted. At the level of C7-T1 therefore it would appear that the cord lesion is the more important and that the relatively robust root is not likely to be damaged in the absence of more severe injury to the softer and more vulnerable spinal cord. The dilemma has therefore not been completely resolved, but on theoretical grounds it would seem beneficial to reduce any displacement if this can be done quickly and safely and within a few hours of the injury.

From this review and this series it is suggested that no attempt should be made to reduce dislocations (without associated fractures) at the C7-T1 level if the patient has a complete cord lesion persisting for 24 hours, and that if the cord lesion is incomplete open reduction should only be attempted by an experienced surgeon who can reduce the displacement gently and quickly. If conditions are not ideal it is probably better to leave the displacement unreduced and prevent further injury by applying moderate skull traction.

\section{REFERENCES}

Brackman R, Vinken PJ. Unilateral facet interlocking in the lower cervical spine. J Bone Joint Surg [Br] 1967:49-B:249-57.

Burke DC, Berryman D. The place of closed manipulation in the management of flexion-rotation dislocation of the cervical spine. $J$ Bone Joint Surg $[B r] 1971 ; 53-B: 165-82$.

Dall DM. Injuries of the cervical spine II. Does anatomical reduction of the bony injuries improve the prognosis for spinal cord recovery? $S A f r$ Med J 1972:46:1083-90.

Evans DK. Reduction of cervical dislocation. J Bone Joint Surg [Br] 1961;43-B:552-5.

Evans DK. Anterior cervical subluxation. J Bone Joint Surg [Br] 1976;58-B:318-21.

Hardy AG. The treatment of paraplegia due to fracture-dislocations of the dorso-lumbar spine. Paraplegia 1965:3:112-23.

Shrosbree RD. Neurological sequelae of reduction of fracture dislocations of the cervical spine. Paraplegia 1979:17:212-21.

Webb JK, Broughton RBK, McSweeney T, Park WM. Hidden flexion injury of the cervical spine. J Bone Joint Surg [Br] 1976;58-B:322-7.

White AA, Southwick WO, Pangabi MM. Clinical instability in the lower cervical spine: a review of past and current concepts. Spine 1976;1: $15-27$. 